\title{
Evaluation of Qualitative Traits In Modified Iranian Red Rey Onion And Comparison Genetic Resistance With Primary Mass Selection And Red Azar- Shahr cv To Fusarium Oxysporum Using Laboratory And Molecular Markers
}

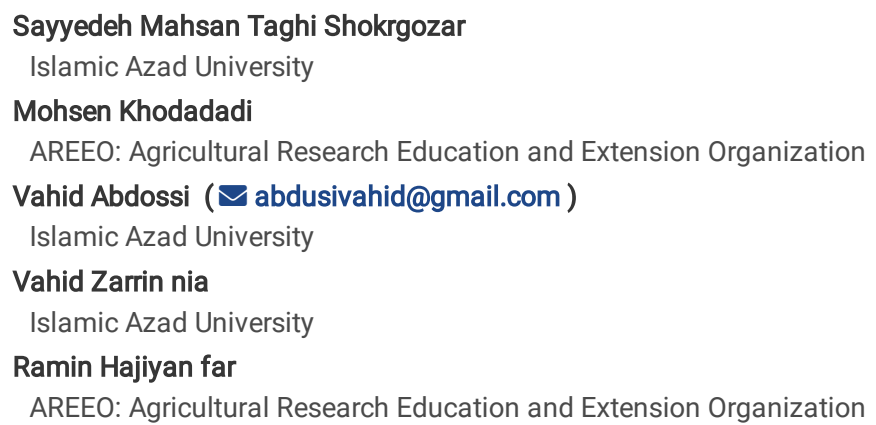




\section{Abstract}

The aim of this study is to evaluate the storage and qualitative feature of modified Red Rey Iranian Onion. Firstly, the modified population was obtained by the selection of superior bulbs, cultivation, its self-pollination and consequently the identification of the best families and implement open pollination between them. In next level, the Red Rey Iranian modified with basic population and Red Azar-shahr cultivar (comparative) was crossed. Our results showed that the selection procedure has leading to improvement in variety of traits in population. Also, the modified Red Rey is significantly superior to the base mass in qualitative traits such as: bulb stiffness, bulb dry matter, TSS, total sugar and glucose; So that the percentage of dry bulb content increased from $10.4 \%$ in the basal mass to $11.1 \%$ in the modified Red Rey; while spouring and rotting, minerals, and dry matter, vitamin $\mathrm{C}$ and fructose-reducing sugar was not affected by genotype. In the second step, resistances to Fusarium wilt disease (laboratory and molecular markers) were evaluated. Based on the results of phenotypic evaluation, the modified Red Rey had the lowest rate and level of infection and the highest score. According to the results of genotypic evaluation, there is a very high genetic affinity between resistant and susceptible cultivars.

\section{Introduction}

Allium cepa L. is belonging to the family Alliaceae that is the third most important cultivated vegetable crop with a global yield of dry bulbs 88 million tons. Iranian onion is exported including fresh white, red, and yellow onion with the taste various ranges. Because of nativeness, cultivation and cross-pollination history, Iranian onion has a very rich variety and genetic reserves. Traits of native populations are often undesirable due to their genetic erosion and frequent cultivation so improvement of native cultivars is a priority. Ray population in Tehran and Alborz provinces is often cultivated in an area of about 1000 hectares. In the results of previous experiments all morphotypes of Red Rey, especially No. 13, had high status in terms of yield per hectare. The nonuniformity of this population, time of maturity and relative thickness of the bulb neck was a major problem for the population, which required the cultivar improvement (Mousavizadeh et al. 2006). Local populations in vegetables such as onions are always considered as an important gene treasury in breeding. Onion populations have a high degree of heterozygosis that persists through amphimixis. It is essential to make accurate selection of native bulbs when seeds are produced to maintain the desired traits. Improvement has been done for traits such as quality, yield, uniformity, resistance to diseases, adaptation to different latitudes and agronomic operations. Historically, the method of selecting pollinator-free populations or segregated families has been considered, although using a periodic selection method-breeding yield can be achieved. In a study of Darabi (2005) the local population breeding was carried out by the method of producing pollinator-free cultivars from 1999. The obtained showed that if the planting date and suitable density were observed, this genotype had a high production potential and given the white color and high percentage of the dry matter, the bulb is suitable for processing. The mentioned genotype has a long shelf life and is desired in terms of uniformity in the shape and color of the bulb. The study results on Iranian onion cultivars such as Red Rey showed that this population has a relatively high storage potential (Khodadadi \& Rastegar 1999).

One of the most important fungal diseases of onion in the world is Fusarium head rot disease caused by the soil pathogen Fusarium oxysporum f. sp. cepa which damages the crop and reduced by about $23 \%$ in the field and storage (Hassanzadeh et al. 2018). 18 onion varieties were studied and it was found resistance to the disease during the growing period, while Spanish onion and Mustang hybrids were resistant. Other studies have shown that estimates of heritability for such traits and coefficient of medium to high genotypic variation with moderate genetic yield. By simple selection, the population can be modified for the mentioned traits. It should be noted that the estimation of heritability of traits depends on the studied population, estimation method, location and agronomic conditions.

Therefore, this research was carried out with the aim of studying of qualitative and storage feature of bulb in Red Rey Iranian modified Onion with maintaining and improving total yield. In addition, evaluation genetic resistance to Fusarium oxysporum f. sp. Cepa was investigated thorough laboratory and molecular markers.

\section{Materials And Methods}

These 2 experiments activities was accomplished in two assays during 2012-2016 in the field of Seedling and Seed Breeding Institute of Karaj located in $35.48^{\circ} \mathrm{N} 50.58^{\circ} \mathrm{E}$

Experiment 1: selecting best families and evaluation of storage and qualitative traits. At first step, Seed Morphotype No. 13, as the best among the Red Rey morphotypes was planted in spring 2012 (base population). Suitable bulbs were harvested up to 500, kept in the cold store (Oct. 2012), cultivated in (March 2013), 300 superior plants were selected and then netting was created on them for self-seeding (June 2013). Selfed seeds were prepared separately from each branches and stored. 100 self-pollinated seeds were cultivated in Mid-April 2014. Bulbs of the 5 best families were selected and stored until March 2014 (yield, early maturity and bulb uniformity) and then planted in the field (March 2015) (Fig. 1). At second step, pollination occurred between plants in spring 2016; seed is now sown in July 2016, named as modified seeds. Finally, modified Red Rey seed along with primary seed (base) and Red Azar-shahr (comparative) were used in completely random block design in 3 replicates (Taghishokrgozar et al. 2020). Investigation of important breeding traits including storage characteristics was calculated.

Experiment 2: Resistances to Fusarium wilt disease (laboratory and molecular markers). Isolates F. oxysporum .f.sp.cepae were incubated in the dish containing the Potato Dextrose Agar and suspension obtained was adjusted to $4 \times 10^{5} / \mathrm{mL}$. Three onion bulbs were artificially inoculated in the laboratory with the invasive isolate and placed germination room. After the required time, the extent of the disease-induced lesion on the head and roots was investigated using the scoring method. To evaluate the genetic resistance of onion lines and masses, first the genomic DNA of the studied cultivars was extracted using Thermo scientific kit. To design the target primers, the nucleotide sequence of the target genes was obtained from (www.ncbi.nlm.nih.gov). PCR products appeared as seen by the presence of related band and without smear. For investigation of genetic mechanism of resistance, the sources of 15 genes that were 
documented to be effective in resistance to fungal diseases, especially Fusarium, was selected. An attempt was made to use an onion-related sequence to design the primer for all genes. After obtaining gene sequences by the NCBI Primer Designing Tool, primers were designed for all genes.

Data analysis. In this study, SPSS V.19 software was used to analyze data. Also, analysis of variance of traits and comparison of their means were performed using Duncan's multiple range tests at $5 \%$ level.

\section{Results}

Experiment 1: selecting best families and evaluation of storage and qualitative traits. In the former study by authors concerning selected families, yield (The best families in terms of statistical rank of 68 and 94), early maturity (top are 57 and 56) and bulb uniformity (best number of bulb uniformity is number 6 ) had been investigated (Taghishokrgozar et al. 2020).

Evaluated storage traits (Red Rey modified seed along with primary seed (and Red Azar-shahr modified). The results revealed that the percentage of weight loss in the Red Azar-shahr with $22.67 \%$ has a minimum range. In the primary population, it has a superior priority of $25.73 \%$ and in the modified cultivar with 24.67\%; so it can be said that, a significant improvement has not been made compared to the primary population and Red Azar-shahr. According to the results of analysis of variance, no significant difference was observed in the percentage of rotten and germinated bulb.

Evaluated qualitative traits (Red Rey modified seed along with primary seed (base) and Red Azar-shahr modified). The results indicate that there is no significant difference between the genotypes in the amount of mineral elements, Vitamin $\mathrm{C}$ and fructose level. In terms of bulb stiffness, it seems that in the modified Red Rey has a rank of "a" with $7.60 \mathrm{~N} / \mathrm{cm}$ and is not in the same level with the primary mass cultivar "b" with $7 \mathrm{~N} / \mathrm{cm}$. This trait with an average of $6.67 \mathrm{~N} / \mathrm{cm}$ in Red Azar-shahr has the grade of "c". The percentage of dry bulb content is relatively higher in the modified mass than the primary mass. The modified Red Ray improved TSS with (11.40\%) compare with Red Azar shahr. As shown in Table 1, total bulb sugar ranks a, b and c, respectively, in the modified Red Ray, base mass and Red Azar-shahr.

Table 1

The results of the mean comparison of qualitative traits in improved population of the basic and control cultivar

\begin{tabular}{|c|c|c|c|c|c|c|c|c|c|c|c|c|}
\hline sov & DF & $\begin{array}{l}\text { Bulb } \\
\text { stiffness }\end{array}$ & $\begin{array}{l}\text { Total } \\
\text { sulfur }\end{array}$ & $\begin{array}{l}\text { Total } \\
\text { phosphor }\end{array}$ & $\begin{array}{l}\text { Total } \\
\text { potassium }\end{array}$ & $\begin{array}{l}\text { Dry } \\
\text { matter }\end{array}$ & $\begin{array}{l}\text { Vitamin } \\
\mathrm{C}\end{array}$ & TSS & $\begin{array}{l}\text { Total } \\
\text { sugar }\end{array}$ & fructose & $\begin{array}{l}\text { Weight } \\
\text { lost }\end{array}$ & sprouting and rotting \\
\hline $\begin{array}{l}\text { Red Rey } \\
\text { modified }\end{array}$ & 2 & $7.60 \mathrm{a}$ & $0.47 a$ & $0.447 a$ & $2.210 \mathrm{a}$ & $11.14 a$ & $8.20 a$ & $11.40 \mathrm{a}$ & $49.97 a$ & $19.83 a$ & $24.67 a$ & $15.23 a$ \\
\hline $\begin{array}{l}\text { Base } \\
\text { seed }\end{array}$ & 2 & $7.00 \mathrm{~b}$ & $0.48 a$ & $0.0431 a$ & $2.060^{\mathrm{a}}$ & $10.44^{a b}$ & $7.86 \mathrm{a}$ & $9.80 \mathrm{~b}$ & $44.33 b$ & $19.10 \mathrm{~b}$ & $25.73 a$ & $16.70 a$ \\
\hline $\begin{array}{l}\text { Red } \\
\text { Azar- } \\
\text { shahr }\end{array}$ & - & $6.67 c$ & $0.57 a$ & $0.385 a$ & $2.237 a$ & $9.64 b$ & $7.963 b$ & 10.17ab & $41.67 \mathrm{c}$ & $19.73 a$ & $22.67 a$ & $13.73 a$ \\
\hline
\end{tabular}

Means within each column followed by the same letter are not different according to the Duncan test.

Table 2

The results of the mean comparison of storage traits in improved population of the basic population and control cultivar

\begin{tabular}{|lllll|}
\hline SOV & DF & Infected rate & Infected score & Infected surface \\
\hline Red Rey modified & 2 & 0c & $5 \mathrm{a}$ & 0c \\
\hline Base seed & 2 & $16.67 \mathrm{~b}$ & $4.8 \mathrm{a}$ & $6.167 \mathrm{~b}$ \\
\hline Red Azar-shahr & - & $100 \mathrm{a}$ & $33 \mathrm{~b}$ & $100 \mathrm{a}$ \\
\hline
\end{tabular}

Experiment 2: Resistances to Fusarium wilt disease (laboratoryand molecular markers). The infected surface, rate and score were significantly affected by the treatment at $1 \%$. Our funding showed that the highest rate of infection was observed in Red Azar-shahr (100\%) and the lowest in the modified mass ( $0 \%$ ).

According to Table (2), the maximum infection score was seen in the modified cultivar and the lowest in the Red Azar-shahr. Also, infected surface was related to the highest in Red Azar-shahr and lowest modified mass. According to the general aim of the study, it was tried to determine the mechanisms used by resistant cultivars to resist Fusarium wilt or, conversely, the mechanisms that have caused susceptibility in cultivars. Based on the amplification of Flavonolsynthase gene (Fig. 2), Anthocyanidin synthase gene (Fig. 3), Trypsin inhibitor gene (Fig. 4), Pentose phosphate phosphatase gene (Fig. 5), SERK1 and MYB1 genes (Fig. 6), WRKY1 gene (Fig. 7), Pectin methyl esterase gene (Fig. 8), two samples on the left section are linked to susceptible cultivars and the portions on the right are closed to treatment in resistant cultivars. In LOX2 and Invertase genes, intermediate segment are bound to the susceptible cultivars and both side of treatment samples are connected with resistant cultivars (Fig. 9). In Thioni and LTP genes, two samples next to the size indicator (100 bp) are associated to sensitive cultivars whereas the other two reigns are treatment (resistant cultivars) (Fig. 10).

\section{Discussion}

Based on the results of phenotypic evaluation of this study, the lowest rate and surface of infection were observed in the modified mass and then the basal mass, respectively. Also, the highest score was seen in the modified mass and then the basal mass. Regarding to the results of genotypic evaluation, there is a very high genetic affinity between resistant and susceptible cultivars. Transcription factors MYB, bHLH2, and WRKY1 are mainly involved in pathways associated with stress hormones such as jasmonic acid and abscisic acid. There are numerous studies of their role in resistance to fungal and bacterial 
diseases such as Xanthomonas and Botrytis (Yu et al. 2018). MYBs are also implicated in the metabolism of secondary metabolites (Rawat, 2016). Cycling of pentose phosphate and glycolysis pathways in response to disease is well known, and given that phosphoenolpyruvate phosphatase is one of the key enzymes in the glycolysis pathway, It was expected that the cause of the difference in disease resistance may be related to this gene. Chalcone isomerase is also involved in the response to ultraviolet light, fungal and bacterial diseases (Dao et al. 2011). Lox2 is one of the key genes in the production of the plant hormone jasmonic acid, which plays an important role in the response to live stress (Tamaoki et al. 2013). Antimicrobial proteins are found in all groups of organisms and have different roles in various organisms against microbial diseases. These proteins are found in onions and many onion families. CaAMP1 is one of these protein-hosts (Kong et al. 2018). Flavonol synthase and flavonol accumulation due to overexpression of this enzyme is one of the known mechanisms in response to biotic and abiotic stresses (Lu et al., 2017). SERK1 is a kinase protein that has a known role in transmitting the message of various diseases including Fusarium wilt (Tang et al. 2017). Pectinases are enzymes that help microbes pathogenesis by breaking down the plant cell wall. In contrast, pectinase blockers such as pectin methylesterase can help plants against microbes (Liu et al. 2018). Gutathione transferases important for various physiological processes, especially during abiotic stress, the cell maintains oxidation-reduction balance, and their effect on oxidative stresses (Sharma et al. 2014). They break down peptides host cell are broken down by proteolytic bacteria and subsequently used either in growth. Protein inhibitors such as trypsin inhibitor are one way to counteract the host against plant pathogens (Moulin et al. 2014). Anthocyanins are plant pigments that are also involved in microbial resistance. Invertases are enzymes that convert sucrose in cells into fructose and glucose, which their role in disease resistance has been proven (Liu et al. 2015). The lachrymatory factor synthase gene is a very important gene in onions, because of its pungent odor and tears when chopping onions; also, it causes a lot of changes in the sulfur-containing metabolites in the cell. It has been proven that sulfur compounds in cell defense play an important role against pathogens (Bloem et al. 2015). The importance of thionine gene in resistance to Fusarium wilt disease has been demonstrated (Asano et al. 2013). According to the results of DNA amplification by PCR, it seems that the difference between sensitive and resistant cultivars is not related to the presence or absence of a gene. In other words, the results of studying the presence of genes among susceptible and resistant cultivars show that among the studied genes, all genes present in susceptible cultivars are also present in resistant cultivars. However, the two genes, antimicrobial peptide and bHLH transcription factor, were not amplified, which may be related to the presence of polymorphisms in the primer binding region. Also, the presence of bands other than the main band can be due to duplication in the genome. This is the case with the ANS, OTI, LOX2 and invertase genes. Since this condition was seen in both resistant and susceptible cultivars, they can not be attributed to the resistance factor in the resistant cultivar or the susceptibility factor in the susceptible group. However, because not all of the genes involved in resistance have been studied in this study, it may be due to resistance in other genes. Therefore, to find out the cause of resistance, it is better to use methods that include the whole genome or the whole transcript. Many experiments proved that two organisms, despite their great genetic affinity, show completely different reactions to the same trait, due to the small differences in the sequence and expression of their genes (Ma t al. 2018; Plissonneau et al. 2017).

In general, considering the results of this research in the molecular part, it showed that firstly, there is a very high genetic similarity between two resistant and sensitive cultivars. Because all the genes found in the resistant are also present in the susceptible and, conversely, all the genes that are not amplified in the resistant and are not amplified in the susceptible. Second, resistance probably depends on the sequence of these genes and the extent to which they are expressed, not on their presence or absence.

\section{Declarations}

\section{ETHICAL STATEMENT}

"This research received no specific grant from any funding agency in the public, commercial, or not-for-profit sectors." "The authors declare that there is no conflict of interest regarding the publication of this article." "All procedures followed were in accordance with the ethical standards of the responsible committee on human experimentation (institutional and national). Informed consent was obtained from all patients for being included in the study."

\section{References}

1. Asano T., Miwa A., Maeda K., Kimura M., Nishiuchi T. (2013): The secreted antifungal protein Thionin 2.4 in Arabidopsis thaliana suppresses the toxicity of a fungal fruit fody Lectin from Fusarium graminearum. PLoS Pathogens, 9: 34-45

2. Bloem E., Haneklaus S., Schnug E. (2015): Milestones in plant sulfur research on sulfur-induced-resistance (SIR) in Europe. Front Plant Science, 5: 212220

3. Dao T.T.H, Linthorst H.J.M, Verpoorte R. (2011): Chalcone synthase and its functions in plant resistance. Photochemistry Review, 10: $397-412$

4. Darabi A.S. (2005): Improvement of local onion in Behbahan by the method of producing pollinator free cultivars. Final report of Khuzestan Agricultural and Natural Resources Research Center. p.12

5. Hassanzadeh Khankhadani H., Khodadadi M., Darabi A., Saleh J., Bagheri A., Faghihi M., Shahriari A. (2018): Guide to Edible Onions (Planting, Holding, Harvesting), Chapter Five. Special mobilization plan with the farmer, Agricultural Research, Education and Extension Organization and Basij Organization of Agricultural Engineers and Natural Resources, Agricultural Research Institute and Food Security, 194 pages. (In Persian)

6. Khodadadi M., Rastegar J. (1999): Study growth pattern and yield of several cultivars and populations of Iranian onion based on physiological indicators. Seedlings and Seeds, 4: 659-675

7. Kong X., Yang M., Abbas H.M.K, Wu J., Li M., Dong W. (2018): Antimicrobial genes from Allium sativum and Pinellia ternata revealed by a Bacillus subtilis expression system. Scientist Reports, 8(1):145-152

8. Liu J., Han L., Huai B., Zheng P., Chang Q., Guan T., Kang Z. (2015): Down-regulation of a wheat alkaline/neutral invertase correlates with reduced host susceptibility to wheat stripe rust caused by Puccinia striiformis. Journal of Experimental Botany, 66: 7325-7338 
9. Liu N., Sun Y., Pei Y., Zhang X., Wang P., Li X., Hou Y. (2018): A Pectin Methylesterase Inhibitor Enhances Resistance to Verticillium Wilt. Plant Physiology, 176: 2202-2220

10. Lu Y., Chen Q., Bu Y., Luo R., Hao S., Zhang J., Yao Y. (2017): Flavonoid Accumulation Plays an Important Role in the Rust Resistance of Malus Plant Leaves. Front Plant Science, 8: 34-44

11. Ma X., Keller B., McDonald B.A., Palma-Guerrero J., Wicker T. (2018): Comparative Transcriptomics Reveals How Wheat Responds to Infection by Zymoseptoria tritici. Molecular Plant-Microbe Interaction, 31: 420-431

12. Moulin M.M., Rodrigues R., Ribeiro S.F.F., Gonçalves L.S.A., Bento C.S., Sudré C.P., Gomes VM. (2014): Trypsin inhibitors from Capsicum baccatum var. pendulum leaves involved in Pepper yellow mosaic virus resistance. Gen Molecular Research, 13: 9229-9243

13. Mousavizadeh S.A., Moghadam M., Torchi M., Mohammadi A., Masiha S. (2006): Morphological and Agronomic Diversity of Indigenous Iranian Onion populations. Iran Journal of Agriculture Science, (2): 193-202

14. Plissonneau C., Benevenuto J., Mohd-Assaad N., Fouché S., Hartmann F.E., Croll D. (2017): Using population and comparative genomics to understand the genetic basis of effectors-Driven fungal pathogen evolution. Front Plant Science, 32-39

15. Rawat N. (2016): Plant Defense Gene Regulation and Transcription Factor Dynamics. Rice Research, 4: 83-92

16. Sharma R., Sahoo A., Devendran R., Jain M. (2014): Over-Expression of a Rice Tau Class Glutathione S-Transferase Gene Improves Tolerance to Salinity and Oxidative Stresses in Arabidopsis. PLOS ONE, 9: 0092900

17. Taghi Shokrgozar S.M., Khodadadi M., Abdossi V., Zarrin nia V., Hajiyan far R. (2021): Investigation quantitative traits in modified Iranian Red Rey onion (Allium cepa L.) and comparison with primary mass selection and Red Azar-shahr cultivar. European Journal of Horticulture Science. Accepted for publishing in next issues

18. Tang D., Wang G., Zhou J.M. (2017): Receptor Kinases in Plant-Pathogen Interactions: More Than Pattern Recognition. The Plant Cell, 29: 618-637

19. Tamaoki D., Seo S., Yamada S., Kano A., Miyamoto A., Shishido H., Gomi K. (2013): Jasmonic acid and salicylic acid activate a common defense system in rice. Plant Signal Behavior, 8: e24260

20. Yu J., Ai G., Shen D., Chai C., Jia Y., Liu W., Dou D. (2018): Bioinformatical analysis and prediction of Nicotiana benthamiana bHLH transcription factors in Phytophthora parasitica resistance. Genomics.

\section{Figures}
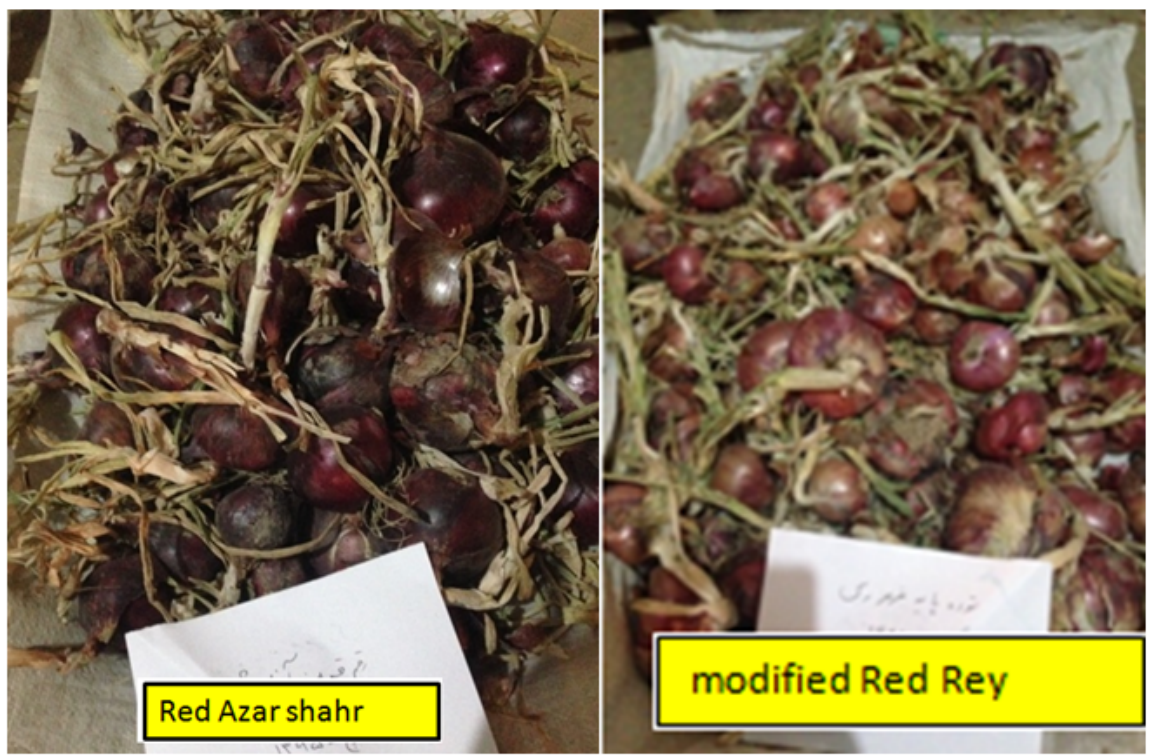

Figure 1

Red Azar shahr and modified Red Rey samples 


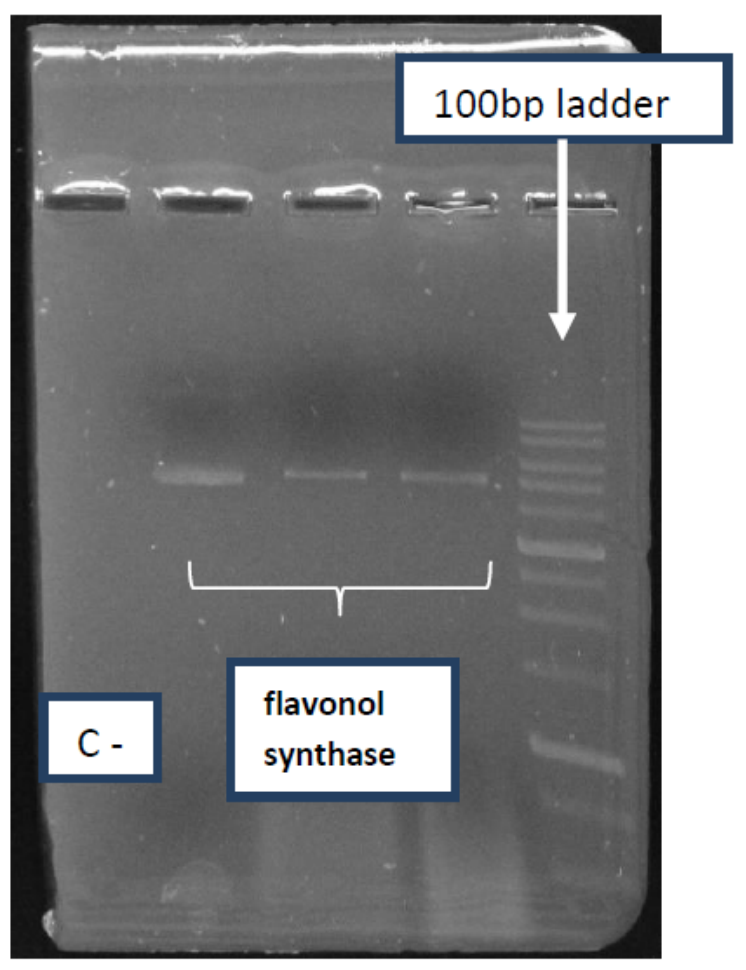

Figure 2

Flavonol synthase gene amplification.

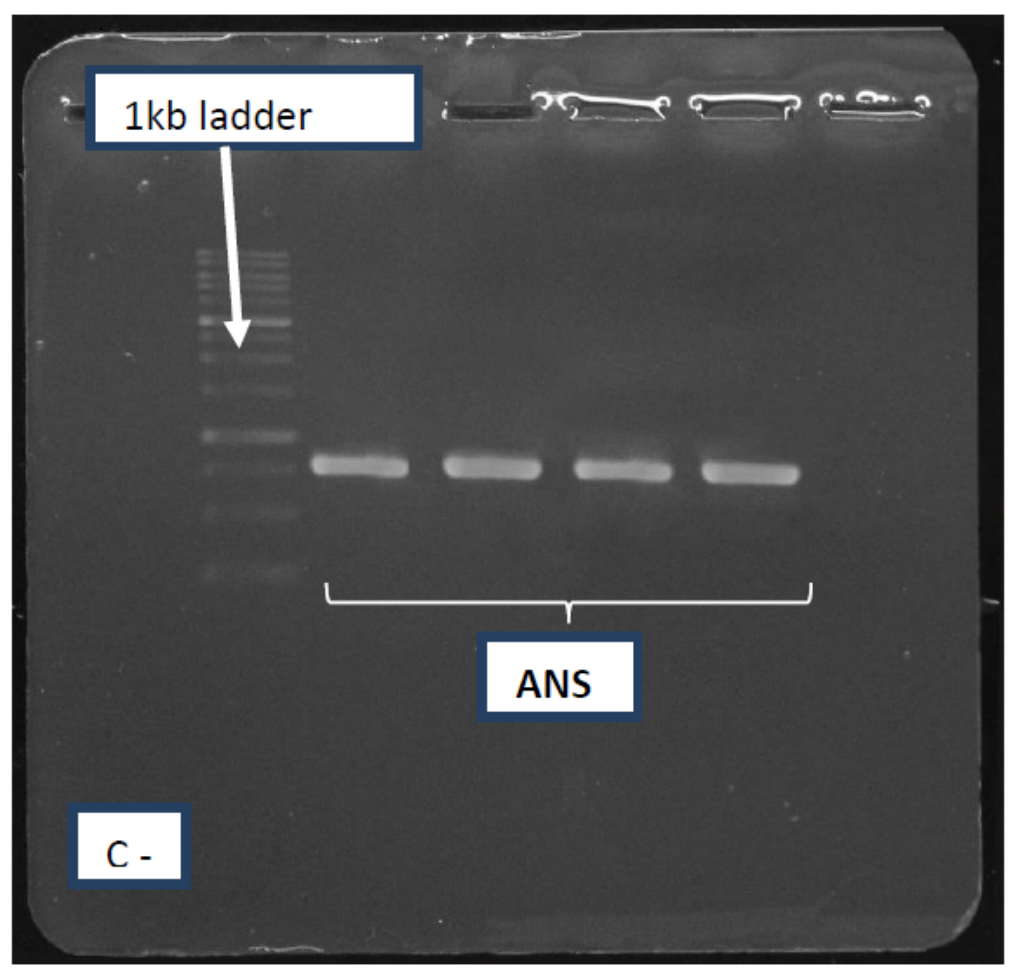

Figure 3

Anthocyanidin synthase gene amplification. 


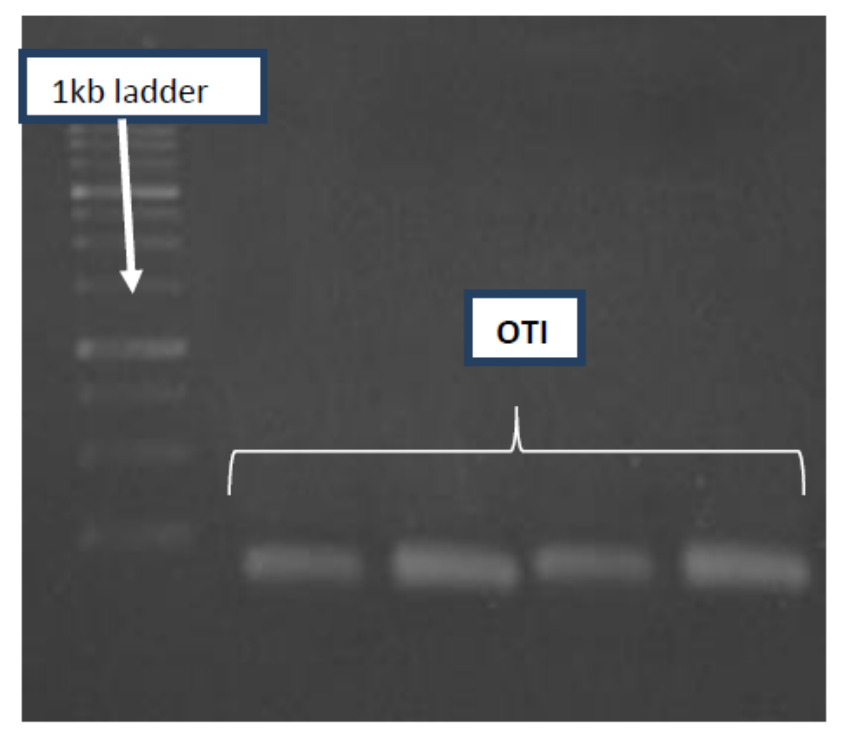

\section{Figure 4}

Trypsin inhibitor gene amplification.

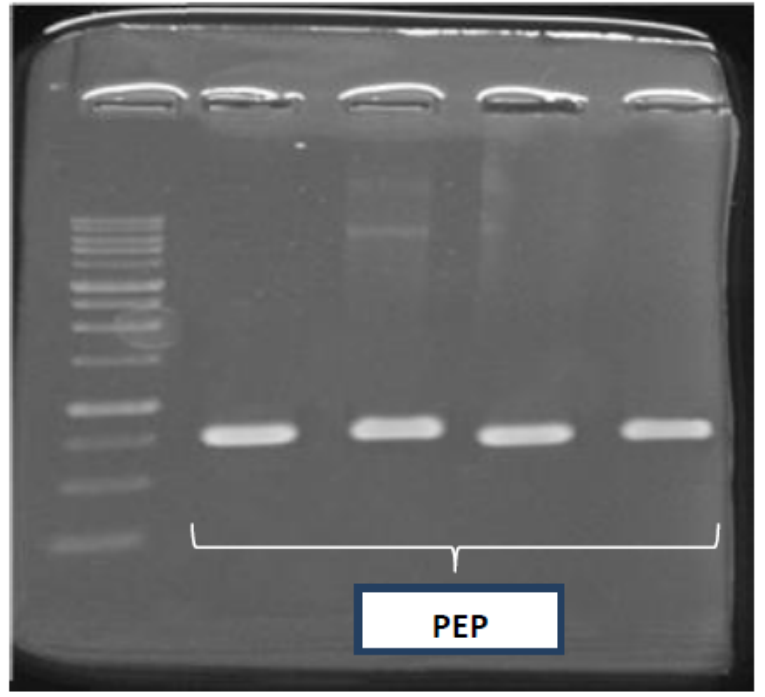

\section{Figure 5}

Pentose phosphate phosphatas gene amplification. 


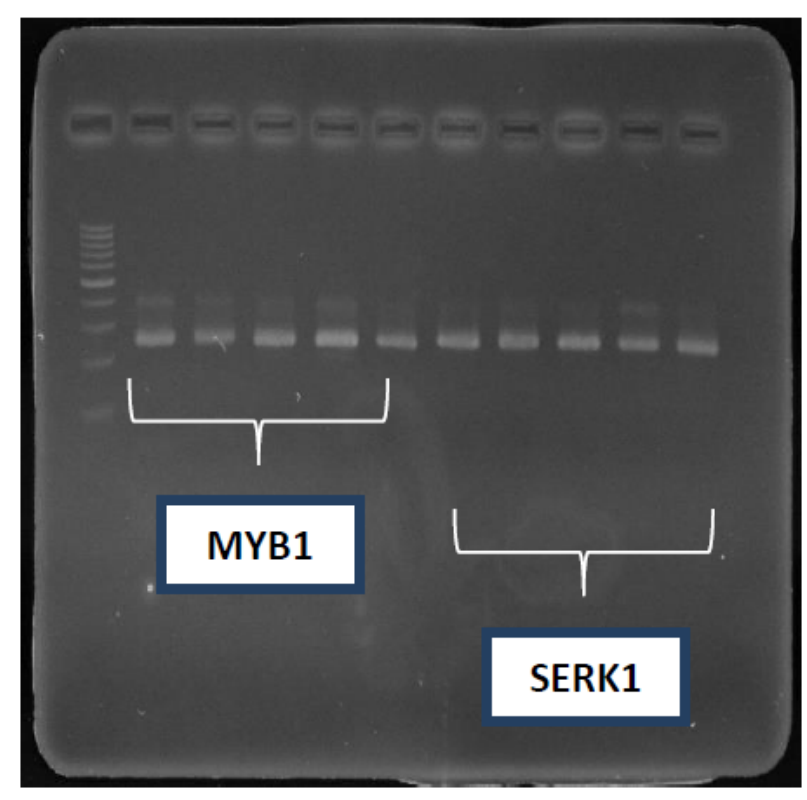

Figure 6

MYB1, SERK1 gene amplification.

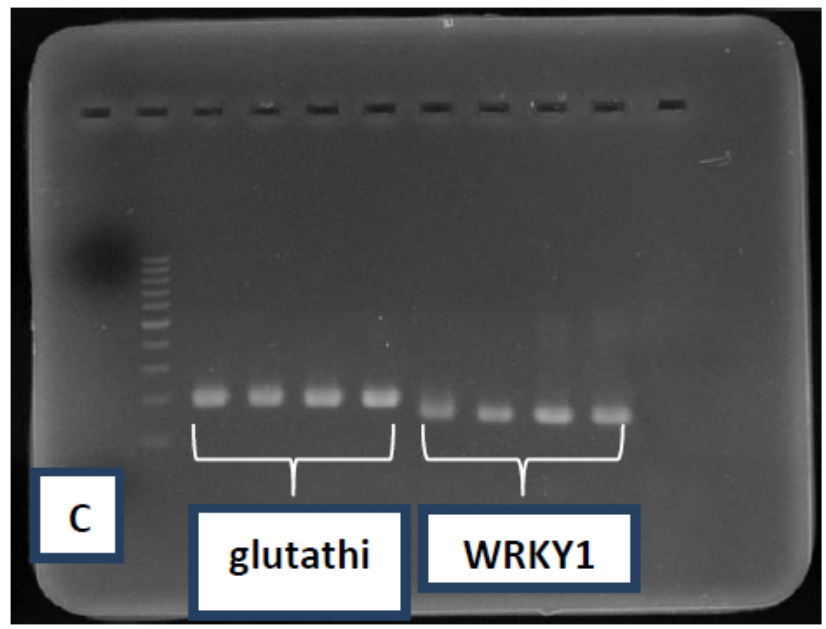

Figure 7

glutathioneS-transferase gene amplification

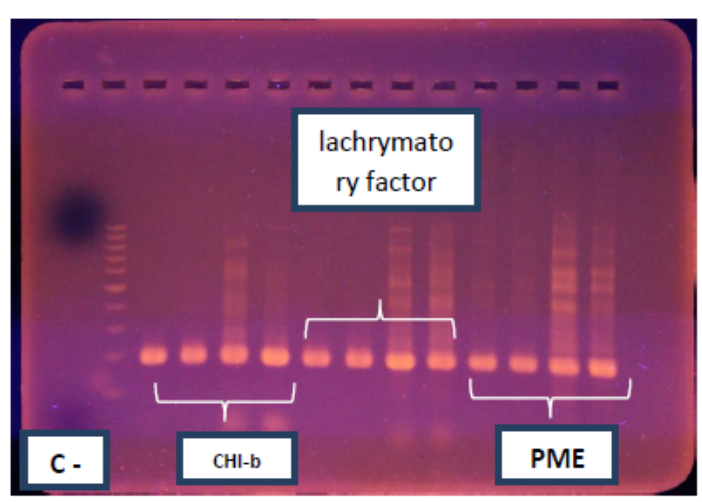

Figure 8

Pectin methyl sterase gene amplification. 


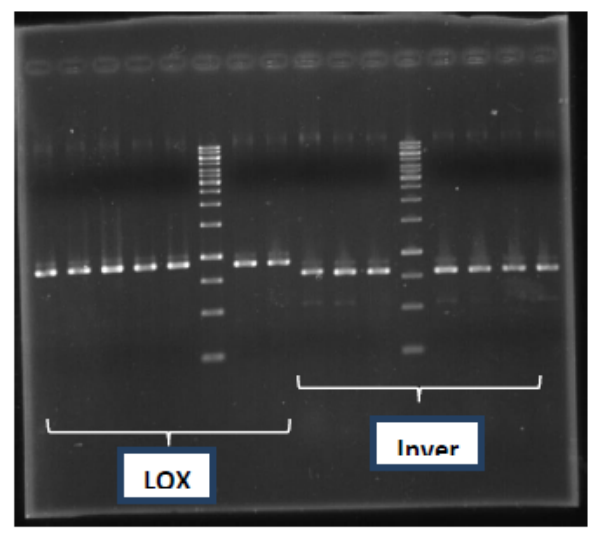

Figure 9

LOX2, Invertase gene amplification.

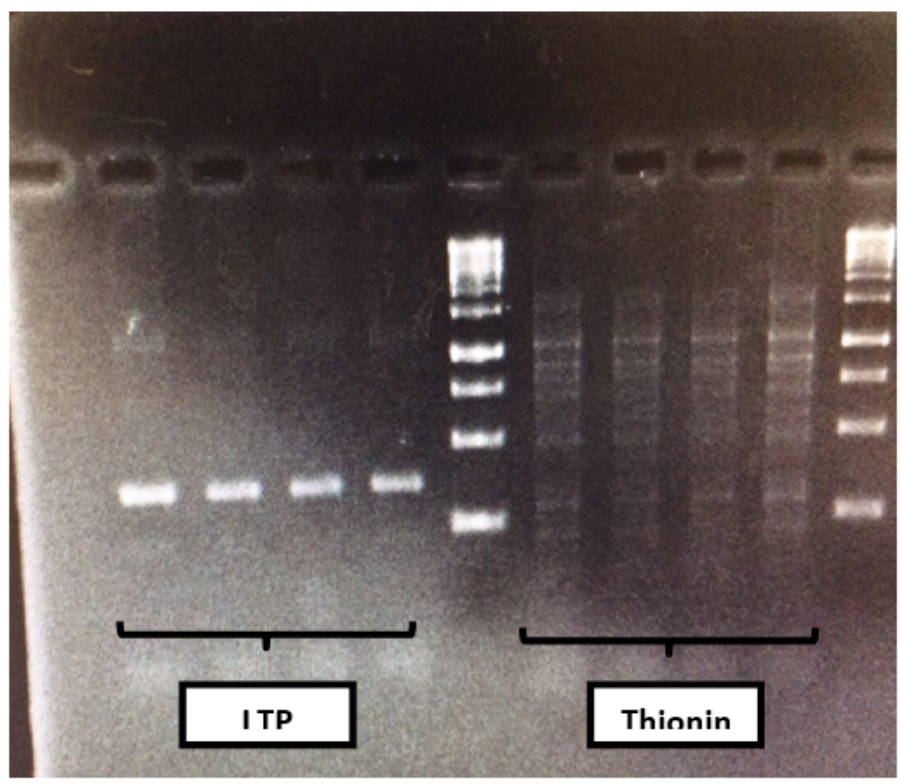

Figure 10

LTP, Thionin gene amplification 